\title{
Exploring the Potential of Digital Teaching Portfolios To Support In/Non-Formal Professional Development For Those Who Teach in Higher Education
}

\author{
Laura Costelloe*1
}

${ }^{\mathbf{1}}$ Mary Immaculate College

\section{Abstract}

This paper will explore the potential of eportfolios - and specifically digital teaching or professional practice portfolios - to support, document and evidence the wealth of nonaccredited and in/non-formal professional learning undertaken by HE teachers to enhance academic practice. Drawing on 28 semi-structured interviews carried out with Irish Higher Education (HE) teachers in three institutions in the Mid-West region and using a qualitative methodology, this paper will consider how digital teaching portfolios offer a space for evidencing and reflecting on engagement in professional learning. Findings point to the recognition of the potential of eportfolios to facilitate the gathering of evidence, artefacts and reflections over an extended period time which can be used at a later stage for accreditation or promotion. Furthermore, participants reported the affordances of eportfolios to recognise the myriad of in- and non-formal professional learning that is undertaken by HE teachers, including experiential and practice-based learning. However, while welcoming the affordances of eportfolios to support engagement in professional learning activities in order to enhance academic practice, there was a perception among some participants that the creation of portfolios is a time-consuming task for which support would be required. Therefore, this study points to the need for a targeted and institutional approaches to support the practice and process of eportfolio development for HE teachers, particularly if a portfolio is to be maximised as a tool of critical reflection and learning to enhance academic practice.

\section{Introduction}

It is broadly recognised that professional development (PD) to enhance academic practice amongst those who teach in Higher Education (HE) encompasses a range of approaches. While there is an established culture of accredited PD provision - particularly for early-career academics - literature points to a preference among more established faculty for nonaccredited or informal PD activities such as workshops, projects, conferences, professional dialogue, experimental approaches or activities related to the scholarship of teaching and learning (Ashgar \& Pilkington, 2018; Kálmán, Tynjälä, \& Skaniakos, 2019; Spowart et al., 2017). The provision of accredited PD is now commonplace in the Irish context and many Irish HE Institutions offer programmes in academic practice at Graduate Certificate, Diploma or Masters Level (M. Maguire, Harding, Noonan, \& O'Connor, 2017; T. Maguire, Tan, \& Rushe, 2015). However, evidence also points to a long-standing culture of engagement in inand non-formal PD activities among Irish HE teachers (Kenny, Young, \& Guilfoyle, 2015). This has been recognised in the Irish National Professional Development Framework (NPDF) 
which is underpinned by an 'acknowledgement of the spectrum of activities that could be considered under the umbrella of PD' (National Forum 2016a; National Forum 2016b). Thus, a considerable amount of the professional learning that is undertaken to enhance academic practice takes place through experiential or work-based practices including communities of practice, conversations with colleagues and practice-based innovations (Knight, Tait, \& Yorke, 2006; Nerantzi, 2015; Warhurst, 2008).

Furthermore, there is a growing body of literature highlighting the use of portfolios to support academic professional learning activities and reflective practice in Higher Education (Costelloe, Gormley, \& O'Riordan, 2019; Hamilton, 2018; Hoekstra \& Crocker, 2015; O'Farrell, 2007; Pelger \& Larsson, 2018). Described as 'a purposeful collection of evidence, consisting of descriptions, documents and examples of what is good teaching for the teacher' (de Rijdt, Tiquet, Dochy, \& Devolder, 2006, p. 1086), portfolios are being used in multiple ways to support PD: to provide evidence of a quality approach to professional development, to document teaching practices for the purposes of promotion, to showcase and reflect on academic practice and to provide evidence of engagement with PD activities. An eportfolio adds an extra dimension to the affordances of a more traditional portfolio through the potential inclusion of multimedia artefacts such as audio, video and text to capture, share and reflect on academic practice.

Bearing in mind the Irish HE context and the relatively recent introduction of the NPDF in 2016 (National Forum for the Enhancement of Teaching and Learning in Higher Education, 2016b), this paper will explore the potential of eportfolios - and specifically digital teaching or professional practice portfolios - to support, document and evidence the wealth of nonaccredited and in/non-formal professional learning undertaken by HE teachers to enhance academic practice. The study aims to answer the following research questions:

(1) To what extent are eportfolios currently used by research participants to support their professional learning to enhance academic practice?

(2) To what extent are eportfolios viewed as a tool to support professional learning to enhance academic practice?

Drawing on 28 semi-structured interviews carried out with Irish HE teachers in three institutions in the Mid-West region, this paper will consider how digital teaching portfolios offer a space to capture, evidence, reflect on and share the wealth of practice-based and in/non-formal PD in which HE teachers engage.

\section{Methods}

This study adopts a qualitative approach, with semi-structured interviews as the primary methodological approach. It is established that qualitative methods are widely used in teaching and learning scholarship (Divan, Ludwig, Matthews, Motley, \& TomlienovicBerbube, 2017) as qualitative research 'allows for in-depth analysis of complex systems and experiences which cannot be fully captured with measurement scales and multivariate models' (Divan et al., 2017, p. 18). In January 2020, following appropriate ethical approval, an invitation to participate in semi-structured interviews was circulated to all staff who teach in three Higher Education institutions in the Mid-West Regional Cluster (University of Limerick, Mary Immaculate College, Limerick Institute of Technology). A total of 28 participants were recruited, which included representatives from both academic staff and professional services roles with teaching responsibilities. The sample also included those in 
management positions (including Deans and Heads of Department), as well as tutors and part-time teaching faculty. Of the 28 participants, 5 already held accredited qualifications in HE academic practice. The sample also included HE teachers with a range of years of experience: 2 participants had less than 3 years' experience; 3 participants had 4-7 years' teaching experience; 2 had 8-11 years' teaching experience; 7 had 12-15 years' teaching experience with the remainder (14 participants) with more than 15 years' experience.

Interviews took place within the context of the FLEXIpath project, which is funded by the National Forum for the Enhancement of Teaching and Learning in Higher Education and aims to design flexible professional learning pathways for those who teach in HE. While the purpose of the interviews was not to probe eportfolio practice per se, in discussions relating to the concepts of flexibility and HE professional development, a number of participants brought up academic practice portfolios and considered their relevance in the context of inand non-formal professional learning activities. Interviews were conducted in real time, predominantly face-to-face, although two interviews were conducted on Skype to enable remote participation. Having given informed consent to participate, interviews were conducted of approximately 45 minutes duration. Interviews were audio-recorded, transcribed and subsequently analysed using NVivo 12, following Braun and Clarke's (2006) six phases of thematic analysis, as follows:

Step 1: Become familiar with the data

Step 2: Coding

Step 3: Searching for themes

Step 4: Reviewing themes

Step 5: Defining themes

Step 6: Writing up

This approach to thematic analysis involves following a series of steps to bring through the researcher firstly through a processes of data familiarisation, followed by initial coding and searching for themes. Themes are subsequently reviewed and then defined in order to assist the final (writing up) stage. Braun and Clarke's (2006) six stage framework has been recognised as being a particularly 'influential' approach within the social sciences (M. Maguire \& Delahunt, 2017, p. 3353) as it facilitates the analysis of both semantic and latent themes: consequently, it enables the surfacing of both explicit data interpretation but also 'underlying ideas, assumptions, and conceptualisations - and ideologies - that are theorised as shaping or informing the semantic content of the data' (Braun and Clarke, 2006: 84). The resultant themes relating to the use of portfolios/digital portfolios as a professional learning tool are now reported.

\section{Findings}

In line with Braun and Clarke's approach outlined above, a thematic map was developed to illustrate the relevant themes present in the data, as well as their relationship to each other and to the research questions; this map is represented in Figure 1: 


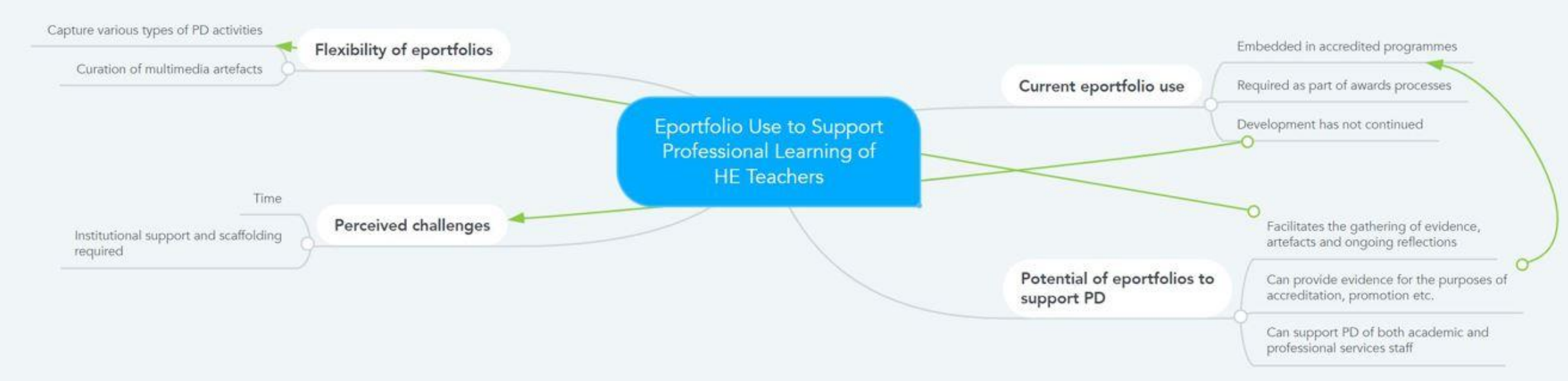

Figure 1: Thematic Map 


\subsection{Theme 1: Current Use of ePortfolios to Enhance Academic Practice}

As mentioned above, the purpose of the broader study from which the data emerged was not to probe eportfolio practice per se; however, in discussions relating to the concepts of flexibility and HE professional development, a number of participants brought up academic practice portfolios and considered their relevance in the context of in- and non-formal professional learning activities. Specifically, of the 28 participants in the study, 11 explicitly referred to the relevance of professional practice portfolios to support flexible approaches to professional development, without being prompted to do so. A number of participants in the study discussed their previous experiences of creating teaching and learning portfolios (not specifically digital or electronic), particularly in the context of the requirements of an accredited programme or for consideration for a teaching award. For example, both Participant 1 (Lecturer) and Participant 11 (Lecturer) remarked that they had previously created a teaching and learning portfolio as part of the process for consideration for a regional teaching excellence award. Participant 1 viewed it as having been a 'very worthwhile' process, observing that institutional support for portfolio development outside of the 'competitive process' of a teaching award would like be a 'really valuable' support for those seeking to enhance their academic practice. Additionally, Participant 20 (Librarian) noted the benefits of developing a teaching and learning portfolio as a requirement for an accredited programme a number of years previously:
And I thought it was a great idea at the time, but unfortunately, [my portfolio] has fallen by the wayside. I would like to get that going again. But I think it's really important, because, you know, if you're in the process, I suppose, when you're given guidance to whoever it is that you're reflecting on that as well. And that kind of helps you to reflect and I suppose change things around as well (P20, Librarian)

However, all three participants cited above remarked that their portfolio development had stalled following their engagement in either an accredited programme or awards process, and thus the impetus for updating their portfolio had dissipated in the absence of a requirement to continue development. This finding is further explored and considered below as it points to the importance of support and scaffolding, for not only the creation of digital of digital teaching and learning portfolios, but also to encourage HE teachers to update and maintain these portfolios following their initial development.

\subsection{Theme 2: Potential of ePortfolios to Support Professional Learning to Enhance Academic Practice}

The potential of digital teaching portfolios to support the professional learning of those who teach in Higher Education emerged through discussions with a number of participants in this study. For example, participants recognised the potential of eportfolios to facilitate the gathering of evidence, artefacts and reflections over an extended period time which can be used at a later stage for accreditation or promotion. This is reflected in the following comments from participants, for example:

Time and again, people are devising the portfolio while they're doing their practice. We should be devising the portfolio as per normal somewhere inside your HR, you should have your best practice portfolio as per normal inside the Core Portal or something like that. And then that that can go 
forward correctly documented and all of that, so that that can go forward to whatever you want to do with it (P13, Librarian)

Similarly, Participant 16 (Lecturer) reported that they engage in professional learning through 'taking on courses or going to events, the conferences or what that I think that I will learn from'; for them, 'being able to record that' would be particularly important and they noted a keenness 'to have that digital portfolio available and easy to populate'. Additionally, Participant 22 (Lecturer) argued for the importance of adopting a broad view of professional development for those who teach in HE:
So, I think we should look at being a bit more creative about professional development for academics and maybe, you know, it's almost like practicing what you preach. Move away from ... you do this programme and then you'll be a better teacher. That as you're teaching you dip into the supports as you need them. You build up a portfolio alongside that, and maybe that's what you present at the end of the day. [....] It's flexible in that you can populate as you go along and that you're informed and encouraged to do that (P22, Lecturer)

The extracts above highlight the recognition from participants in this study that engagement in PD is an ongoing activity for those who teach in HE, and eportfolios offer a useful space for keeping track of activities undertaken. Furthermore, they provide evidence which can be used for the purposes of accreditation, promotion etc. at a later stage, should that be appropriate. Participants thus recognised the flexibility of eportfolios as a versatile tool of showcase, assessment or learning (Scully, O'Leary, \& Brown, 2018; discussed further below). It is perhaps interesting to note also that the extracts above include participants from both academic and professional services staff; this highlights the importance of adopting a broad view of a HE 'teacher'. This is exemplified in the NPDF which aims for an inclusive definition of 'all staff who teach' in HE which includes the following: academic staff across disciplines; educational/learning technologists; educational/academic developers; research staff; library staff; support staff and students who teach others e.g. graduate teaching assistants and those who engage in peer assisted learning' (National Forum for the Enhancement of Teaching and Learning in Higher Education, 2016b, p. 1). HE teachers in various roles engage in professional learning to further develop and support their teaching, learning and assessment practices and eportfolios offer a flexible and versatile tool which can be used in varying ways to support this learning.

\subsection{Theme 3: Flexibility of eportfolios}

Furthermore, participants discussed how an eportfolio can recognise the myriad of in- and non-formal professional learning that is undertaken by HE teachers, including experiential and practice-based learning. Consider the following excerpts, for example:

I've learned about new pedagogies or new methods or formats of delivery, but now I can also customize. Even building into the portfolio because I think, again, depending on individuals and where they're at in their career, part of what they're doing is developing their teaching portfolio. (P12, Head of Department) 
And some of that was maybe they attended conferences in their particular area, just to upskill on, you know, what's going on out there. Maybe they might have contributed to webinars, for example. So there's a lot of good work going on in that space. I think just somewhere to be able to look back and say, Wow, you know, I've done all this. (P16, Lecturer)

The two quotations above exemplify the growing recognition that professional learning takes many guises beyond structured, accredited programmes. Such a broad interpretation is increasingly recognised in the literature surrounding the professional development of $\mathrm{HE}$ teachers: for example, Malik et al. (2015, p. 169) suggest that 'professional development encompasses all types of facilitating knowledge opportunity, ranging from university degrees to formal assignments, conferences and informal learning opportunities located in practice'.

Likewise, the NPDF proposes a 'typology' of PD activities which involves both accredited and non-accredited professional learning, including collaborative, unstructured and structured (National Forum for the Enhancement of Teaching and Learning in Higher Education, 2016b, pp. 1-2). Thus, developing and maintaining a digital teaching and learning portfolio offers $\mathrm{HE}$ teachers a space to evidence engagement in in- and non-formal professional development (e.g. conferences and webinars as mentioned by Participant 16 above).

Furthermore, eportfolios offer considerable flexibility in relation to capturing and sharing professional learning through various modes. For example, Participant 16 (Lecturer) compares the 'ring binder' version of the first portfolio that she created in 2007 and recognises that a more contemporary version would be best created in a digital format in order to capture the breadth of PD activities in which she engages:

\section{So, the digital teaching portfolio [...] it could be a variety of things. So, if I were looking at mine, it would be my WordPress blog. It would be my stuff on Twitter, it would be any one of a number of things that I'm out there on.}

The quotation above highlights that HE teachers are using a variety of modes and platforms to engage in professional learning, and therefore require a flexible, multimedia platform in order to capture, evidence and reflect on such engagement. A movement away from the paper-based 'ring binder' style portfolio towards electronic platforms offers greater choice and flexibility and also the use of audio, video, imagery and text-based artefacts.

\subsection{Theme 4: Perceived Challenges}

Finally, while welcoming the affordances of digital teaching and learning portfolios to support engagement in professional learning activities in order to enhance academic practice, there was a perception among some participants that the creation of portfolios is a timeconsuming task for which support would be required. For example, Participant 17 (Lecturer) mentioned that 'it sounds like so much work', while Participant 22 (Lecturer) similarly commented that 'putting together a portfolio - but there's a lot of work in that'. It is perhaps unsurprising therefore that some participants recognise the need for structures and supports in order to scaffold the portfolio-building process: Participant 24 (Professor) pointed to the importance of 'ongoing support in what it means to create a high-quality portfolio', and similarly Participant 22 (Lecturer) spoke about the importance of ease and usability when it comes to any proposed institutional professional development portfolio: 
So I think it's important that people are given a portfolio profile. They start it from the moment they arrive. In relation to teaching and learning, research, any of those elements, but for professional development, we're talking about your whole professional development, I think that would be really useful. But that there's an easy way to actually populate the portfolio. Yeah, I think that's really important. And particularly if you're very busy, and you don't have time to be spending filling in forms.

Thus, for participants in this study, while there was certainly a recognition of the potential of eportfolios as a tool to document, reflect on and ultimately enhance academic practice, there was a belief that the portfolio development process would be a time-consuming process which would benefit from scaffolding and supports. The issue of time as a barrier to engagement in professional learning is well documented in the literature; for example, Botham's (2018) analysis of the factors that affect engagement of HE teachers with an institutional PD scheme explored the concept of time as a barrier and identified three challenges: lack of time, need for deployed hours and participants' good time management/intrinsic motivation. Furthermore, the recent results of the Irish National Digital Experience (INDEx) Survey (National Forum for the Enhancement of Teaching and Learning in Higher Education, 2020) highlighted strong calls from Irish HE teachers for more institutional support to develop digital capabilities, including time, support to innovate and reward/recognition for when they develop the digital aspects of their role. Therefore, this study suggests that if the potential of eportfolios to support in/non-formal PD for those who teach in HE is to be harnessed to it's full potential, then greater consideration is needed for the institutional supports that must be provided to scaffold the eportfolio development process.

\section{Discussion}

The findings above highlight the recognition that for HE teachers, eportfolio practice can serve many purposes and can be targeted towards varying audiences, depending on the reason(s) for which a portfolio is created. Smith and Tillema (2003) identify four types of portfolio for HE teachers: the dossier portfolio, the training portfolio, the reflective portfolio and the personal development portfolio. This was echoed by the participants in this study, who recognised that a digital portfolio can be oriented towards differing audiences and purposes. Digital portfolio platforms offer such flexibility and enable the sharing of artefacts, evidence and reflections in various formats and with various audiences.

Participants in this study support the findings in the literature which point to PD as an ongoing activity for many HE teachers which encompasses both formal and informal professional learning. There is evidence that much of the PD undertaken - particularly by more experienced HE teachers - tends to encompass informal or work-based practices, including networking, communities of practice, conversations with colleagues and practicebased innovations (Knight et al., 2006; Nerantzi, 2015; Warhurst, 2008). Roscoe (2002, p. 5) describes such approaches to professional learning as 'spontaneous and opportunistic, reacting to direct experience of the individual circumstances'. Seldin (2006) maintains that the PD needs of experienced HE teachers are likely to differ from the needs of more junior colleagues, and literature points to a preference among more established faculty for nonaccredited or informal PD activities (Ashgar \& Pilkington, 2018; Biglan, 1973; Kálmán et al., 
2019; Spowart et al., 2017). Participants in this study acknowledge the significant learning that is gleaned through conferences, peer learning and practice-based experiential learning, and recognise the potential of digital teaching and learning portfolios as spaces within which to capture and reflect on such learning. Evidence suggests that many accredited programmes in academic practice are targeted at early-career HE teachers (Ross et al., 2016; Thomas, Harden-Thew, Delahunty, \& Dean, 2016), and thus there is a need for recognition mechanisms for professional learning undertaken by more experienced teachers. Hamilton (2020, p. 162) argues that 'evidence-based teaching portfolios are an effective form of authentic, contextualised, continuous professional development', and this study supports the view that eportfolios offer potential as a tool to support the ongoing professional learning of HE teachers, particularly with regard to engagement in in- and non-formal PD.

However, the study also points to the importance of scaffolding and support to ensure that the potential of digital teaching portfolios to support academic practice is maximised. Hamilton (2020, p. 162) maintains that 'the way in which the portfolio is developed, mentored and scaffolded mediates its effectiveness and authenticity'. Thus, simply having an eportfolio is unlikely in and of itself to yield to the enhancement of academic practice; rather, it is iterative processes of continual reflection that can pave the way. It has been argued that institutional support is critical to successfully implementing portfolios as a means to strengthen and enhance faculty growth and development' (Caldwell, Foster, \& Ring, 2017, p. 85). Participants in this study echo these observations and call for structured and institutionallysupported mechanisms for the development of eportfolios to document, evidence and reflect on PD undertaken to enhance academic practice.

\section{Conclusion}

This paper explored the potential of eportfolios - and specifically digital teaching or professional practice portfolios - to support, document and evidence the wealth of nonaccredited and in/non-formal professional learning undertaken by HE teachers to enhance academic practice. Through a series of semi-structured qualitative interviews undertaken with a cross-section of those who teach in HE across three institutions in the Mid-West region in Ireland, this study highlighted the enormous potential of eportfolios as a tool to support professional learning to enhance academic practice. The study provides a snapshot of current teaching and learning portfolio use among Irish HE teachers, with participants in this study indicating that the impetus for creating a portfolio stemmed from a requirement from an accredited programme or as part of an application for a teaching and learning award (either local, regional or national). It is interesting to note that of those participants who indicated that they had previously created a portfolio, there is no evidence that the development of these portfolios had continued beyond the required submission period. This underscores one of the key findings of this study, which is the importance of institutional scaffolding and support - including both protected time and digital skills development - in order to enable HE teachers to maximise the potential of eportfolios to support their professional learning. The study highlighted the flexibility of eportfolios as a tool to capture, evidence and reflect on the myriad of in- and non-formal professional learning activities in which HE teachers engage, but greater support is needed if such flexibility is to be harnessed to its maximal potential. Therefore, the study points to the need for an institutional approach to sustain the practice and process of eportfolio development, particularly if a portfolio is to be used as a tool of critical reflection and learning. Caldwell et al. (2017, p. 85) maintain that 'institutional support is critical to successfully implementing portfolios as a means to 
strengthen and enhance faculty growth and development', and this study suggests that in the absence of such institutional support, eportfolio use to as a tool of professional learning is perhaps unlikely to develop beyond contexts where they are required (e.g. accredited programmes or awards schemes). Nonetheless, this study contributes to a growing body of literature which recognises the potential of eportfolios to support in- and non-formal professional development for those who teach in HE, through offering flexible and multimodal spaces to capture and reflect on a broad range of professional learning activities. Indeed, as O'Keeffe and Donnelly (2013, p. 2) argue, 'the real potential for ePortfolios is in the widening contexts in which learning is taking place - or is recognized to be taking place - and in their ability to bring together personal learning gained in multiple contexts'.

\section{Funding Acknowledgement}

The FLEXIpath 'Professional Development Capacity Building in Higher Education: Extending provision for national impact through a flexible pathways approach' project is funded by the National Forum for the Enhancement of Teaching and Learning in Higher Education. 


\section{References}

Ashgar, M., \& Pilkington, R. (2018). The relational value of professional dialogue for academics pursuing HEA fellowship. International Journal for Academic Development, 23(2), 135-146. doi:10.1080/1360144X.2017.1386566

Biglan, A. (1973). The characteristics of subject matter in different academic areas. Journal of Applied Psychology, 57(3), 195-203.

Botham, K. A. (2018). An analysis of the factors that affect engagement of Higher Education teachers with an institutional professional development scheme. Innovations in Education and Teaching International, 55(2), 176-189.

Braun, V., \& Clarke, V. (2006). Using thematic analysis in psychology. Qualitative Research in Psychology, 3(2), 77-101.

Caldwell, H., Foster, G. R., \& Ring, G. (2017). Faculty Eportfolios: teaching and learning and professional development In T. Batson, K. S. Coleman, H. L. Chen, C. E. Watson, T. L. Rhodes, \& A. Harver (Eds.), Field Guide to Eportfolio (pp. 82-91). Washington DC: Association of American Colleges and Universities

Costelloe, L., Gormley, C., \& O'Riordan, F. (2019). Walking the talk: academic developers reflect on the use of digital learning portfolios to support professional development. Educational Developments, 20(4), 11-13.

de Rijdt, C., Tiquet, E., Dochy, F., \& Devolder, M. (2006). Teaching portfolios in higher education and their effects: an explorative study. Teaching and Teacher Education, 22, 1084-1093. doi:https://doi.org/10.1016/j.tate.2006.07.002

Divan, A., Ludwig, L., Matthews, K., Motley, P., \& Tomlienovic-Berbube, A. (2017). A survey of research approaches utilised in the Scholarship of Learning and Teaching publications. Teaching \& Learning Inquiry, 5(2), 16-29.

Hamilton, M. (2018). Bridging the Gap from Teacher to Teacher Educator: the role of a teaching portfolio. Studying Teacher Education, 14, 88-102. doi:10.1080/17425964.2017.1414041

Hamilton, M. (2020). Evidence-based portfolios: a cross-sectoral approach to professional development among teachers. Professional Development in Education, 46(1), 160174.

Hoekstra, A., \& Crocker, J. R. (2015). ePortfolios: enhancing professional learning of vocational educators. Vocations and Learning, 8(3), 353-372.

Kálmán, O., Tynjälä, P., \& Skaniakos, T. (2019). Patterns of university teachers' approaches to teaching, professional development and perceived departmental cultures. Teaching in Higher Education, 25(5), 595-614. doi:10.1080/13562517.2019.1586667 
Kenny, N., Young, K., \& Guilfoyle, L. (2015). A Snapshot of Non-Accredited Continuing Professional Development for Those who Teach in Irish Higher Education. Retrieved from https://www.teachingandlearning.ie/publication/a-snapshot-of-non-accreditedcontinuing-professional-development-for-those-who-teach-in-irish-higher-education/

Knight, P., Tait, J., \& Yorke, M. (2006). The professional learning of teachers in higher education. Studies in Higher Education, 31(3), 319-339.

doi:10.1080/03075070600680786

Maguire, M., \& Delahunt, B. (2017). Doing a thematic analysis: a practical, step-by-step guide for learning and teaching scholars. AISHE-J: The All Ireland Journal of Teaching and Learning in Higher Education, 8(3), 3351-33514.

Maguire, M., Harding, N., Noonan, G., \& O'Connor, T. (Eds.). (2017). Teachers as Learners: exploring the impact of accredited professional development on learning and teaching in Irish Higher Education. Maynooth: AISHE.

Maguire, T., Tan, E., \& Rushe, N. (2015). A snapshot of accredited professional development provision in Irish higher education. Retrieved from https://www.teachingandlearning.ie/publication/a-snapshot-of-accreditedprofessional-development-provision-in-irish-higher-education/

Malik, S. K., Nasim, U., \& Tabassum, F. (2015). Perceived effectiveness of professional development programs of teachers at Higher Education level. Journal of Education and Practice, 6(13), 169-181.

National Forum for the Enhancement of Teaching and Learning in Higher Education. (2016a). A conceptual model for the professional development of those who teach in Irish Higher Education: report on the findings of the consultation process. Retrieved from https://www.teachingandlearning.ie/publication/a-conceptual-model-for-theprofessional-development-of-those-who-teach-in-irsh-higher-education/

National Forum for the Enhancement of Teaching and Learning in Higher Education. (2016b). National Professional Development Framework for All Staff Who Teach in Higher Education. Retrieved from https://www.teachingandlearning.ie/wpcontent/uploads/NF-2016-National-Professional-Development-Framework-for-allStaff-Who-Teach-in-Higher-Education.pdf

National Forum for the Enhancement of Teaching and Learning in Higher Education. (2020). INDEx Findings from Students and Staff Who Teach in Higher Education. Retrieved from https://www.teachingandlearning.ie/wp-content/uploads/NF-2020-INDEx$\underline{\text { Report.pdf }}$

Nerantzi, C. (2015). Who says academics don't do CPD? Connecting practitioners and developing together through distributed cross-institutional collaborative CPD in the Open. Journal of Perspectives in Applied Academic Practice, 3(1), 98-108. doi:10.14297/jpaap.v3i1.136

O'Farrell, C. (Ed.) (2007). Teaching Portfolio Practice in Ireland: a handbook. Dublin: AISHE. 
O'Keeffe, M., \& Donnelly, R. (2013). Exploration of ePortfolios for adding value and deepening student learning in contemporary Higher Education. International Journal of ePortfolio, 3(1), 1-11.

Pelger, S., \& Larsson, M. (2018). Advancement towards the scholarship of teaching and learning through the writing of teaching portfolios. International Journal for Academic Development, 23(3), 179-191. doi:10.1080/1360144X.2018.1435417

Roscoe, J. (2002). Continuing professional development in higher education. Human Resource Development International, 5(1), 3-9.

Ross, B., Carbone, A., Lindsay, K., Drew, S., Cottman, C., \& Stoney, S. (2016). Developing educational goals: insights from a Peer Assisted Teaching Scheme. International Journal for Academic Development, 21(4), 350-363.

Scully, D., O'Leary, M., \& Brown, M. (2018). The Learning Portfolio in Higher Education: a game of snakes and ladders. Dublin: Dublin City University Centre for Assessment Research, Policy \& Practice in Education (CARPE) and National Institute for Digital Learning (NIDL).

Seldin, P. (2006). Tailoring faculty development programs to faculty career stages. In S. Chadwick-Blossey \& D. R. Robertson (Eds.), To Improve the Academy: resources for faculty, instructional and organizational development (pp. 137-146). Bolton, MA: Anker.

Smith, K., \& Tillema, H. (2003). Clarifying different types of portfolio use. Assessment \& Evaluation in Higher Education, 28(6), 625-648.

Spowart, L., Winter, J., Turner, R., Muneer, R., McKenna, C., \& Kneale, P. (2017). Evidencing the impact of teaching-related CPD: beyond the "Happy Sheets". International Journal for Academic Development, 22(4), 360-372. doi:10.1080/1360144X.2017.1340294

Thomas, L., Harden-Thew, K., Delahunty, J., \& Dean, B. A. (2016). A vision of You-topia: personalising professional development of teaching in a diverse academic workforce. Journal of University Teaching and Learning Practice, 13(4), 1-12.

Warhurst, R. P. (2008). 'Cigars on the flight-deck': new lecturers' participatory learning within workplace communities of practice. Studies in Higher Education, 33(4), 453467. doi:10.1080/03075070802211828 